\title{
CRÍTICA AOS FUNDAMENTOS DA PSICOLOGIA EM POLITZER: PSICANÁLISE E PSICOLOGIA CONCRETA
}

\section{José Luiz Pastre}

\section{RESUMO}

O artigo apresenta uma leitura do livro Crítica aos fundamentos da psicologia, de Georges Politzer. Nele, Politzer realizou sua leitura da obra A Interpretação dos Sonhos, de Freud, para construir as bases do que denominou psicologia concreta. O propósito é acompanhar o movimento que Politzer fez para demonstrar a sobrevivência da abstração na psicologia nascente, mas, também, acompanhando o movimento que ele fez para mostrar as potências dessa nova psicologia. Para acompanhar esse movimento, consideramos três conjuntos de questões, que aparecem no livro de Politzer como sendo importantes para que a nova psicologia possa constituir-se: a definição do fato psicológico; definição de um método; e, criação de noções próprias.

\section{PALAVRAS-CHAVE}

Drama; Fato psicológico; Método; Inconsciente

\section{CRITICAL TO FUNDAMENTALS OF PSYCHOLOGY IN POLITZER: PSYCHOANALYSIS AND PSYCHOLOGY CONCRETA}

\begin{abstract}
This article presents a reading of Politzer's book A Critique to the fundaments of Psychology, where the author, from reading Freud's "Interpretation of Dreams", tried to construct the bases for what he considered to be a concrete psychology. We undertook this reading trying to follow the movement Politzer makes towards demonstrating the survival of abstraction in the emergent psychology, but, also, following the movement that he makes towards showing the potencies of the new psychology. By accompanying this movement, we consider three sets of issues that appear in Politzer's text as being important for the new psychology to become: a definition of the psychological fact; a definition of a method; and a creation of his own notions.
\end{abstract}

\section{KEYWORDS}

Drama; Method; Psychological fact; Unconscious

\footnotetext{
- Este texto é uma versão modificada de um capítulo de minha dissertação de mestrado em que procurei tratar da relação eu-outrem-mundo na obra de Maurice Merleau-Ponty. Meus agradecimentos ao professor Márcio Mariguela pela leitura da versão atual e por algumas indicações técnicas a respeito da obra de Politzer.
}

(C) ETD - Educação Temática Digital, Campinas, v.8, n.esp., p.103-120, dez. 2006 - ISSN: 1676-2592. 


\section{INTRODUÇÃO}

Trataremos, nesse texto, de alguns aspectos da crítica de Politzer aos fundamentos da psicologia e do que ele considera ser o nascimento de uma psicologia concreta.

Politzer aponta a necessidade de uma crítica renovadora da psicologia que ultrapasse a oscilação entre uma psicologia subjetiva (psicologia introspectiva ou conceitual) e uma psicologia objetiva (psicologia de laboratório ou experimental). Esta crítica renovadora deve criar as bases para uma psicologia voltada para o concreto, ou seja, uma psicologia capaz de apreender e interpretar os fatos vividos pelo indivíduo (primeira pessoa), e tem como alvo a psicologia abstrata, ou toda psicologia que assume implícita ou explicitamente os pressupostos da psicologia clássica e que, portanto, pensa o "homem em geral” (terceira pessoa) e se constrói em torno do mito da dupla natureza humana (orgânica e psicológica), ou em torno do que Politzer considera ser a mística burguesa: a vida interior $^{1}$.

Para Politzer, a psicologia clássica se constrói em torno de mitos por não conseguir atender às condições de existência de uma psicologia positiva. Segundo ele, são três as condições de existência de uma psicologia positiva: 1. ser uma ciência a posteriori, ou seja, ser o estudo adequado de um grupo de fatos; 2. ser original, isto é, estudar fatos irredutíveis aos objetos das outras ciências; 3. ser objetiva ou, em outros termos, ser capaz de definir o fato e o método psicológicos, de tal forma que sejam, de direito, universalmente acessíveis e verificáveis(POLITZER,1998:182).Considerando estes critérios Politzer procurou avaliar os esforços de diversas escolas no sentido de dar à psicologia o estatuto de cientificidade. Mas, segundo ele, o que na verdade caracteriza a história da psicologia do final do século XIX e início do século XX é muito mais o esforço para se libertar de seus mitos do que o esforço no sentido de sua organização (POLITZER,1998:38).

\footnotetext{
${ }^{1}$ Em sua apresentação ao livro de Politzer, Osmyr Gabbi Jr. afirmou que, “sob o nome de Psicologia Clássica, Politzer relaciona uma série de pressupostos compartilhados por diversas escolas psicológicas, que certamente não se reconheceriam sob esse título, mas é vital assinalar a unidade profunda que existe por trás da suposta diversidade e da eterna querela das escolas, para quem pretende realizar uma crítica essencial dos fundamentos da psicologia”. (POLITZER, 1998:VI) São cinco os postulados clássicos apresentados por Gabbi Jr.: crença de que a forma última do psicológico é atomística; tese de que o psicológico é apreendido de
} 


\section{SUBJETIVISMO E OBJETIVISMO}

Em sua busca pelo estatuto de cientificidade a psicologia contemporânea recusa o método introspectivo tradicional. O método introspectivo é um método subjetivo, que consiste na observação do sujeito pelo próprio sujeito, ou seja, a introspecção atinge o que o sujeito conhece diretamente e, dessa maneira, somente ele conhece seus estados de consciência, suas impressões vividas a respeito de si mesmo e das coisas. Observar-se a si mesmo não é simplesmente viver as próprias impressões. A impressão vivida deverá ser comunicada, exteriorizada através da linguagem. A função da linguagem é, portanto, relatar os estados subjetivos do indivíduo. Mas, segundo Politzer, em geral, a psicologia introspectiva tradicional preocupa-se mais em saber como o processo mental se desenvolve, ou em classificar os estados individuais, do que buscar o sentido da experiência vivida pelo sujeito (POLITZER,1998:80).

A psicologia experimental se opõe a este método justamente pelo seu caráter subjetivo, pois uma das características do método objetivo é o fato de o observador ser distinto do observado. A psicologia experimental toma como modelo de cientificidade as ciências da natureza, mais especificamente, a física e a matemática. Por exemplo, segundo o método experimental o observador deve verificar os fatos físicos: por um lado, a situação física a que está exposto o sujeito; por outro lado, sua conduta, seu comportamento nessa situação. Ao contrário dos estados de consciência individuais, tais fatos físicos podem ser conhecidos por diversas testemunhas, cujas observações se controlam mutuamente (GUILLAUME,1967:2-10). Mas também podemos citar como exemplos o fato de em seus laboratórios os fisiólogos procurarem estabelecer a relação entre o número de células cerebrais para saber se o cérebro é capaz de abrigar todas as idéias, ou ainda, estabelecer o papel das funções fisiológicas na emoção etc. Politzer afirma que preconizando uma psicologia “sem alma”, procurando superar os limites da introspecção tradicional, no meio dos aparelhos, o psicólogo ora se lança na fisiologia, ora na química ou na biologia, e ao

forma imediata pela percepção; presunção de que existe uma vida interior; crença de que o psíquico resulte de processos e não de atos de pessoas concretas; postulado da convencionalidade do significado.

(c) ETD - Educação Temática Digital, Campinas, v.8, n.esp., p.103-120, dez. 2006 - ISSN: 1676-2592. 
invés de se deixar renovar pelo espírito científico, utiliza-o para dar vida a velhas tradições (POLITZER,1998:39-40).

\section{I - O NASCIMENTO DA PSICOLOGIA CONCRETA}

Em meio ao esforço de diversas escolas em dar à psicologia o estatuto de cientificidade, Politzer consegue detectar algumas tendências que, ao mesmo tempo em que acaba a dissolução dos mitos da psicologia clássica, prenunciam a nova psicologia. São elas: a psicologia da forma, o behaviorismo de Watson e, principalmente, a psicanálise (POLITZER,1998:46). Para Politzer, apesar de suas contribuições, essas tendências acabam incorrendo em erros que as afastam de sua orientação para o concreto. Isto ocorre na medida em que tratam o comportamento humano como resultado de processos em terceira pessoa, ou como atos do homem em geral, e não como atos de um sujeito concreto. No entanto, estes erros não eliminam totalmente os seus méritos e as suas contribuições no sentido de renovação da psicologia.

Por exemplo, para Politzer, o grande valor da teoria da forma está em sua negação do procedimento fundamental da psicologia clássica, que consiste em afirmar que a essência última do psicológico é atomística. Segundo ele, a psicologia clássica desfaz a forma das ações humanas para tentar, depois, reconstituir a totalidade, que é sentido e forma (grifos do autor), a partir de elementos insignificantes e amorfos (POLITZER, 1998:46). Para a teoria da forma o psíquico só pode ser entendido como totalidade e não enquanto elementos distintos que são posteriormente associados. No entanto, subsiste na teoria da forma a tese de que o psicológico é aprendido de forma imediata pela percepção (POLITZER,1998:VII).

A contribuição do behaviorismo de Watson está em sua negação radical da psicologia clássica, introspeccionista ou experimental, sendo que uma de suas denúncias mais importantes diz respeito ao caráter mitológico de uma tese muito cara à psicologia clássica: a presunção de que existe uma vida interior. Segundo Osmyr Gabbi, a tese da vida interior, é o último refúgio do animismo - pois equivale a acreditar que há seres dentro de

(C) ETD - Educação Temática Digital, Campinas, v.8, n.esp., p.103-120, dez. 2006 - ISSN: 1676-2592. 106 
nós que agem, têm intenções e são dotados de vida própria -, e leva necessariamente a dirigir a atenção do psicólogo para processos internos que, não sendo de natureza fisiológica - caso contrário seriam objeto da fisiologia e não da psicologia -, têm de ser pensados como de natureza representativa (POLITZER,1998: VII-VIII). Mas, apesar de contribuir com a dissolução de antigos mitos da psicologia com a noção de comportamento (behavior), o behaviorismo não consegue superar totalmente esses mitos e acaba suprimindo o enigma do homem. Isto ocorre na medida em que reduz seus estudos a respeito do comportamento humano a seus aspectos fisiológicos ou introduz, de forma disfarçada, aquilo mesmo que rejeita, a introspecção. $O$ behaviorismo não trata 0 comportamento enquanto "drama" humano. Para Politzer, o termo vida designa um fato biológico, ao mesmo tempo em que a vida propriamente humana seria a vida dramática do homem, e é esta vida dramática que, segundo ele, apresenta todas as características que tornam uma área suscetível de ser estudada cientificamente (POLITZER, 998: 43).

Segundo Politzer é a partir da psicanálise que podemos realmente perceber a verdadeira psicologia (POLITZER,1998: 49). Para ele, a tarefa da psicologia científica é deixar falar o concreto, e isto ocorre com a psicanálise, pois ela permite ao psicólogo adquirir certa sabedoria do real, ultrapassando o plano da linguagem para captar algo do mistério que seu objeto encerra. Segundo ele, até então a verdadeira psicologia havia se refugiado na literatura e no drama, vivendo à margem, ou mesmo fora, da psicologia oficial, como a física experimental teve de viver, inicialmente, à margem da física especulativa, oficial (POLITZER,1998:55).

Buscando o que considera ser a verdadeira inspiração da psicanálise, Politzer toma como exemplo a "Interpretação dos Sonhos" (Traumdeutung) de Freud, por considerar que é nesta obra que melhor aparece o sentido da psicanálise e onde são mostrados com um cuidado e uma clareza extraordinários seus procedimentos constitutivos e, portanto, onde pode-se perceber a sua diferença em relação à psicologia clássica (POLITZER,1998:51). A partir da análise desta obra, Politzer afirma que a contribuição da psicanálise não está na descoberta de processos inconscientes ou mesmo do próprio inconsciente, mas, sim, em sua nova definição do que vem a ser um fato psicológico, deslocando o interesse das entidades

(C) ETD - Educação Temática Digital, Campinas, v.8, n.esp., p.103-120, dez. 2006 - ISSN: 1676-2592. 107 


\section{ARTIGO \\ Grupo de Estudos e Pesquisa Diferenças e Subjetividades em Educação Grupo de Leitura de Freud}

espirituais para a vida dramática do indivíduo (POLITZER,1998: 103). Vejamos algumas de suas conclusões.

\section{A PROPÓSITO DO CONTEÚDO DOS SONHOS}

A psicologia clássica trata os elementos do sonho de um ponto de vista abstrato e formal $^{2}$. Politzer chama de abstração o procedimento que consiste em objetivar os fatos psicológicos. No caso do sonho seria tratá-lo como um conjunto de estados, como resultado de um processo impessoal, como tendo causas mecânicas, como sendo uma entidade que existe em si mesma, e não como ato de um sujeito. Assim, o conteúdo intervém para ser classificado em geral: das imagens no sonho, dos estados afetivos etc., a partir de um ponto de vista da classe. Desconsidera-se a individualidade do sonho, o sentido que o sonho tem para o indivíduo, destacando-o do sujeito de que o sonho é. Afinal, o sonho é considerado, não como feito pelo sujeito, mas como se fosse produzido por causas impessoais.

Um outro exemplo de uma atitude de abstração seria compartimentar o indivíduo em faculdades. Politzer cita a teoria das faculdades da alma como sendo o mais representativo exemplo de abstração. Nessa teoria o eu (primeira pessoa) é compartimentado em faculdades independentes (consciência, tendência, memória etc.), de onde provém os fatos psicológicos.

Ora, a psicanálise procura compreender os fatos psicológicos em função do sujeito e não como resultado de processos impessoais. Não só o sonho, mas também as neuroses e os atos falhos, são produzidos por um sujeito (POLITZER,1998:59-62).

\section{II - DEFINIÇÃO DE FATO PSICOLÓGICO}

Primeiramente Politzer distingue o fato físico do fato psicológico. Por exemplo, a lâmpada que ilumina uma escrivaninha é um fato “objetivo”, precisamente por estar em “terceira pessoa”, por não ser “eu”, mas “ela”. Porém, segundo a natureza do ato que a põe, a lâmpada, que é um fato físico, também pode ser tomada como um fato psicológico, na

\footnotetext{
${ }^{2}$ A abstração é o procedimento fundamental de toda a teoria clássica.
}

(C) ETD - Educação Temática Digital, Campinas, v.8, n.esp., p.103-120, dez. 2006 - ISSN: 1676-2592. 108 
medida em que sou eu (moi $)^{3}$ que lhe subentendo o ser. Ora, a psicologia clássica, com seu realismo, se dispõe a estudar os fatos psicológicos tirando o sujeito que o subentende, ou seja, se dispõe a estudar os fatos da primeira pessoa em terceira pessoa. Nesse sentido, a psicologia clássica separa por um lado o eu (moi) e, por outro lado, os fatos psicológicos, que são considerados como diversos aspectos dos atos do "eu", como encarnações da mesma forma do "eu". O eu (moi) é causa dos fatos de consciência (quem é olhado/lugar) ou sujeito da introspecção (quem olha/síntese). Como já dissemos, a psicologia clássica estuda os fatos psicológicos em terceira pessoa e só depois se preocupa em vinculá-los a um sujeito (POLITZER,1998:62-66). Qual é o eu da psicologia?

Para Politzer, a psicologia só pode existir como ciência empírica e, nesse sentido, o eu da psicologia só pode ser o indivíduo particular, ou seja, os atos de um indivíduo concreto, e não o indivíduo em geral, ou os atos de um sujeito transcendental. Nesse sentido, o fato psicológico deve ser pessoal e atualmente pessoal, ou seja, o ato é o fato psicológico real, é a única noção inseparável do eu. Portanto, Politzer entende por drama humano (pessoal) os acontecimentos vividos pelo indivíduo, e que expressam o que se passa com o indivíduo todo. Por exemplo, o sonho deve ser vinculado à experiência concreta do indivíduo, sendo uma modulação do "eu” que o tem, e expressando a continuidade da presença do "eu". Em resumo, a psicologia clássica define o fato psicológico como sendo um processo mental e, nesse sentido, procura estudar o indivíduo observando o que se passa em seu interior, ou classificando os seus estados ou comportamentos em classes e, com isto, reduzindo a vida do indivíduo a um drama abstrato, na medida em que pensa o homem em geral. Já a psicologia concreta, no caso a psicanálise, define o fato psicológico como sendo todo ato do sujeito e, portanto, procura interpretar o sentido dos atos do indivíduo concreto (drama pessoal/indivíduo particular) (POLITZER,1998:67-68). Como posso conhecer o indivíduo em sua particularidade?

\footnotetext{
${ }^{3}$ É interessante notar que Politzer emprega o pronome que indica a primeira pessoa ora utilizando o termo je, ora utilizando o termo moi. Estes diferentes termos, existentes na língua francesa para designar a primeira pessoa, não são usados indistintamente por ele. Trataremos desta distinção técnica no final do texto. A propósito da tradução, os tradutores afirmam empregar o termo eu (je) para designar a primeira pessoa não no sentido técnico que tem em Freud. Mariguela (revisor técnico da tradução) afirma que, quando Politzer utiliza o pronome je, aparece em itálico ou entre aspas, quando se refere ao moi, será indicado. Portanto, em nosso
} 
Vejamos em que o método interpretativo na psicanálise se distingue da introspecção clássica, segundo Politzer.

\section{III - DEFINIÇÃO DO MÉTODO: INTERPRETAÇÃO X INTROSPECÇÃO}

Politzer afirma que a vida psicológica de outro indivíduo pode ser dada sob a forma de "relato" ou de "visão". Sob a forma de relato, quando se trata de expressão por meio da linguagem (em todos os sentidos do termo); sob a forma de visão, quando se trata de gestos ou, em geral, de ação. Segundo ele, o relato e a visão têm função prática e social e sua estrutura é, por isso, finalista: a linguagem corresponde em mim a uma "intenção significativa" e as ações, a uma "intenção ativa". Por sua vez, à intenção significativa em mim corresponde nos outros uma "intenção compreensiva", e quanto à visão, o dia-a-dia respeita o seu plano, afirma ele. Por exemplo: falo, e a vida diária só vê a intenção significativa. Estendo a mão para pegar a garrafa de água, alguém a apresenta. No primeiro caso, sou compreendido; no segundo caso, uma "reação social” responde à minha "ação". Enfim, Politzer afirma que nas relações cotidianas não se sai da "teleologia da linguagem" e fica-se no plano das significações, compreensões e ações recíprocas. Isto posto, ele procura mostrar a diferença entre o método introspectivo (psicologia clássica) e o método interpretativo (psicanálise), a partir do modo como cada qual trata o relato. Em que consiste a crítica de Politzer ao método introspectivo?

É que a introspecção abandona o plano teleológico e faz abstração da intenção significativa, ou seja, o que interessa à psicologia clássica não é o que o sujeito relata, mas o que se passou em sua mente enquanto falava, interessa-lhe o "pensamento" do indivíduo. A psicologia clássica distingue a expressão do expressado e estabelece uma correspondência entre o relato e um processo interior ao indivíduo (processos mentais). É através do relato que o psicólogo pode ter acesso ao processo interior, onde: a expressão é a intenção significativa (a palavra, a fala), e o expressado (idéia) o que se passa no interior do indivíduo, em seu pensamento.

texto, acompanharemos a distinção feita pelos tradutores: eu, sem nenhuma marcação, pronome em primeira pessoa sem distinção técnica; eu (moi) e “eu” ou eu para (je).

(c) ETD - Educação Temática Digital, Campinas, v.8, n.esp., p.103-120, dez. 2006 - ISSN: 1676-2592. 
A psicologia clássica não distingue o sujeito que vive o fato psicológico do sujeito que conhece o fato psicológico. Politzer estabelece a seguinte distinção, a propósito da introspecção: as "percepções internas" simples, que se produzem na continuidade da vida cotidiana como, por exemplo, a dor orgânica, o sofrimento imediato; o relato significativo que é a descrição da experiência vivida; a introspecção sistemática que é aquela feita pelo psicólogo ou pelo sujeito que reflete. Ela é um estudo sistemático das experiências relatadas pelo indivíduo. Mas como a psicologia clássica opera este estudo?

Politzer afirma que o psicólogo clássico desdobra o relato significativo e faz do seu duplo uma realidade "interna”, o psicólogo procura no relato uma imagem “interna”(POLITZER,1998:88). Na introspecção ou reflexão o psicólogo abandona o plano intencional e coloca-se no ponto de vista realista e formal. Ele substitui o primeiro relato, significativo, por um segundo relato, que nada mais tem a ver com a teleologia das relações humanas. A introspecção seria, então, um "segundo relato”. Mas é preciso distinguir este procedimento da psicologia clássica, que consiste em desdobrar o relato, do raciocínio analógico.

A propósito da introspecção, Politzer distingue duas hipóteses: aquelas que procedem por raciocínio analógico daquelas que procedem por desdobramento. Raciocínio analógico: quando afirmo que são meus estados psíquicos que conheço em primeiro lugar e não suponho estados psíquicos em meus semelhantes senão graças à minha própria experiência interna. Se considerar assim, é artificial dizer que desdobro o relato, pois só atribuo aos meus semelhantes estados que, em mim, constituem realmente a duplicação do relato (primado da introspeç̧ão). Desdobramento: quando se toma como primitivo a realização do relato por meio do desdobramento. A introspecção, neste caso, seria uma aplicação a si mesmo de uma atitude tomada face ao relato significativo pelo "senso comum”, a introspecção seria uma atitude segunda e não uma atitude espontânea ${ }^{4}$. O que Politzer chama de "introspecção" seria, então, esse desdobramento (POLITZER,1998:89).

Portanto, o psicólogo espera que, no relato, o sujeito forneça um estudo e não uma narração dos fatos vividos por ele, espera que o indivíduo seja, ao mesmo tempo, o sujeito

\footnotetext{
${ }^{4}$ Primado do desdobramento: projeção em si mesmo da significação convencional.
} 


\section{ARTIGO \\ Grupo de Estudos e Pesquisa Diferenças e Subjetividades em Educação Grupo de Leitura de Freud}

que vive e o sujeito epistemológico. Diferentemente da posição clássica, Politzer afirma a primazia da atitude teleológica, pois, para ele, é a compreensão e a interpretação que estão em primeiro lugar e a psicologia só vem depois. Por sua vez, a expressão e a compreensão não implicam uma experiência interna por parte de quem se expressa, nem a projeção dos dados dessa experiência, na consciência de quem é compreendido (POLITZER, 1998:91). Nesse sentido, é à introspecção sistemática como um todo, tanto à que procede por raciocínio analógico $^{5}$, quanto a que procede por desdobramento ${ }^{6}$, que Politzer dirige a sua crítica e não aos sentimentos imediatos da vida cotidiana. Qual a posição da psicanálise? Voltemos ao modo como ela interpreta o sonho.

\section{INTERPRETANDO O SONHO}

No que diz respeito aos sonhos, para a psicologia clássica não existe um problema de interpretação, pois para ela o sonho não é um ato psíquico, mas sim um fenômeno orgânico, só registrado por certos sinais psíquicos, cujas representações têm existência própria independente do sujeito (POLITZER,1998: 92). Politzer considera a maneira como a psicanálise trata a relação entre o sonho e o relato do sonho. O sonho é considerado como um fato psicológico, no sentido pleno da palavra, ou seja, como um segmento da vida individual. Nesse sentido, é preciso admitir que as fórmulas verbais não exprimem, no relato, o que exprimiriam fora do sujeito, mas precisamente alguma coisa do sujeito e, portanto, para encontrar a vida individual concreta, é preciso remontar além da significação convencional das fórmulas utilizadas pelo sonho. É aqui que aparece a distinção feita por Freud entre conteúdo manifesto (relato convencional) e conteúdo latente (relato em termos de experiência individual) do sonho. Para apreender o sentido do sonho é preciso opor ao relato em termos convencionais um relato feito em termos de experiência individual. A psicologia clássica considera, no relato, apenas o seu conteúdo manifesto, apenas a significação convencional que Politzer chama de postulado da convencionalidade da

\footnotetext{
${ }^{5}$ Que também sofre ataques do behaviorismo.

${ }^{6}$ Que é uma hipótese adotada por parte da psicologia.
} 


\section{ARTIGO \\ Grupo de Estudos e Pesquisa Diferenças e Subjetividades em Educação Grupo de Leitura de Freud}

significação (POLITZER,1998:94). Em que consiste este postulado da convencionalidade da significação?

Trata-se de tomar o valor coletivo da linguagem e dos atos como fato espiritual. Por exemplo, os termos do relato que o sujeito faz de seu sonho têm uma significação ordinária, uma significação pública que podemos encontrar nos dicionários, mas tem também uma significação individual, uma significação para o sujeito. A psicologia clássica, em uma atitude realista, desdobra a significação convencional, a projeta no interior do indivíduo e, não indo além da significação convencional, como se o indivíduo não passasse de uma realização das exigências sociais, elimina o problema do sentido (POLITZER,1998:95-96). Qual a diferença entre significação individual e significação pública, segundo Politzer?

Para Politzer, as significações convencionais não se situam todas no mesmo plano. Elas constituem camadas superpostas, que vão de significações absolutamente convencionais às que o são menos, e supõem uma crescente experiência individual. Portanto, é possível constituir para cada termo o que ele chama de "pirâmide dos sentidos”: uma pirâmide invertida cuja base seria representada pelo sentido que a palavra tem para as pessoas, e o vértice, pelo sentido dado graças à experiência de um único indivíduo. Entre o vértice e a base, situam-se os sentidos que, embora não determinados pela experiência de um único indivíduo, não pertencem a todas as pessoas. Ele nos dá um exemplo: a palavra “chapéu” significa para todos, “agasalho para a cabeça”; “presente”, só para alguns; e “partes sexuais do marido”, só para a senhora cujo sonho Freud analisou em Traumdeutung (POLITZER,1998:97). Para Politzer, somos forçados a interpretar na vida prática, pois todas as significações, exceto a propriamente individual, nos são dadas pela experiência coletiva. Porém a psicologia clássica não vai além das significações convencionais, que se assentam nas manifestações espontâneas da vida social. Então, como apreender a significação individual (íntima)?

Politzer afirma que a estrutura da significação íntima é a mesma da significação convencional. Assim, para encontrar a significação íntima basta proceder da mesma maneira que procedemos para estabelecer uma significação qualquer: é preciso elementos e pontos de referência (contexto). Se as significações são íntimas é porque o indivíduo possui uma experiência secreta. Portanto, no caso do sonho, por exemplo, é preciso tratá-lo como 
um texto a ser decifrado. Segundo Politzer, o procedimento fundamental do método de Freud, para penetrar na experiência secreta do indivíduo, é o método das associações livres. A expressão "associação livre” não é tomada no sentido clássico, onde se admite que há associação em todo lugar onde há uma intenção significativa consciente e em que o sujeito não se inspira expressamente em alguma dialética. Para Politzer, Freud, ao contrário da psicologia clássica, supõe que mesmo que tenhamos renunciado a toda intenção significativa e a toda dialética convencional, nosso pensamento continuará sendo regido por uma dialética e a traduzir uma intenção significativa originais. A vida do sujeito gira sempre em torno de certos temas íntimos (POLITZER,1998:99), mesmo quando ele não tem mais nada "a dizer".

Enfim, ao expor a diferença entre psicologia clássica e a psicanálise, Politzer considera o que interessa a cada um dos métodos, tomando como exemplo o que cada um procura no relato, a partir de como cada um define o fato psicológico. Segundo ele, a introspecção se interessa pela vida interior (os processos mentais) e a psicanálise se interessa pelo sujeito (o sentido de seus atos), nesse sentido, a introspecção, colocando-se em um ponto de vista realista, procura no relato a imagem de uma realidade interna no indivíduo e, a psicanálise, colocando-se no ponto de vista da significação teleológica, procura no relato o sentido dos atos do indivíduo concreto (POLITZER,1998:100-101). Mas em que consiste o problema da psicanálise, segundo Politzer?

\section{IV - DUALIDADE DO ABSTRATO E DO CONCRETO}

Para Politzer o problema da psicanálise está em suas explicações do funcionamento do aparelho psíquico (POLITZER,1998:103-124). Na medida em que, ao explicar a distinção entre conteúdo manifesto e conteúdo latente, Freud introduz a hipótese do inconsciente e explica o comportamento humano a partir de processos interiores, processos em terceira pessoa, ele incorre nos mesmos erros que denunciava na psicologia clássica, e leva-nos, por exemplo, de volta à biologia e ao energetismo: princípio de prazer/princípio econômico (POLITZER,1998:123-126). 
Consideremos a distinção feita por Politzer: o sonho (atitude vivida), o relato do sonho (descrição de uma atitude vivida, relato significativo) e a análise do relato. Politzer afirma que se o sonho e, em geral, os sintomas neuróticos têm algum sentido, o têm no momento em que se produzem e o sentido não é dado pela análise. Para ele, a análise só explica o que o sonho é e o que os sintomas neuróticos são, como esta explicação se dá essencialmente no plano do relato, pode-se dizer que, neste determinado sentido, a análise faz o ser passar para o plano do relato em primeira pessoa e, desse ponto de vista, o conteúdo latente de um sonho ou de um sintoma neurótico nada mais é que uma descrição, isto é, um relato convencional cujo tema é precisamente uma atitude vivida.

Se a análise é necessária, é que o relato do sonho, tal como feito pelo sujeito, não é uma prestação de contas exaustiva do que foi vivido. Como Freud não rompe com o postulado do pensamento convencional ele supõe que a todo comportamento corresponde um relato adequado de onde ele procede, o que significa ter por princípio que não se vive mais do que se pensa. Quando as informações a respeito de um comportamento, obtidas através da análise, se mostram maiores que o indicado pelo relato que o acompanha, projeta-se no inconsciente o que falta ao relato para ser adequado (POLITZER,1998:106107).

Nesse sentido, estabelece-se que o fato psicológico não pode existir senão sob a forma narrativa (POLITZER, 1998:150-151) ${ }^{7}$. O conteúdo latente é considerado como um fato psicológico, mas um fato psicológico sem consciência (POLITZER,1998:106). Freud toma o reflexo como modelo de toda produção psíquica (POLITZER,1998:113). Ele distingue os atos com consciência e atos inconscientes, mas a palavra ato perde o seu sentido dramático e humano, em suas explicações, e passa a ter o mesmo sentido que tem para um fisiólogo, como se fosse um movimento qualquer ou uma nova forma de excitação. Existe, portanto, uma dualidade na psicanálise. É a dualidade do abstrato e do concreto. O abstrato sobrevive nas explicações e o concreto está presente nas descobertas da psicanálise (POLITZER, 1998:163).

Para Politzer o contraste entre a concepção concreta do fato e do método, por um lado, e a atitude abstrata, por outro lado, podem ser explicados pela maneira como Freud 
concebe as relações entre psicologia e psicanálise. Segundo ele, para Freud, psicologia e psicanálise estão em planos diferentes (POLITZER,1998:165). Politzer procura demonstrar tal afirmação considerando o movimento que Freud faz da psicanálise à psicologia e, depois, da psicologia à psicanálise. Para ele, o movimento que Freud faz em direção à psicologia se dá quando este procura explicar suas descobertas. A busca da explicação psicológica implica o abandono da atitude propriamente psicanalítica. Assim, para Freud, explicar o fato psicológico significa encaixá-lo em leis conhecidas da psicologia e, portanto, pelo simples fato de se procurar a explicação, somos levados de volta à psicologia clássica (POLITZER,1998:166). No entanto, o que interessa a Politzer é o movimento que leva Freud da psicologia à psicanálise, pois as descobertas da psicanálise supõem uma concepção da psicologia que não pode coincidir com a psicologia clássica e que levantam um novo problema: saber qual é precisamente essa psicologia nova que fez com que as novas descobertas fossem possíveis (POLITZER,1998:168).

Para Politzer, qualquer que seja a incompatibilidade do seu aspecto técnico com a psicologia concreta, a simples aceitação da hipótese do inconsciente implica uma atitude totalmente contrária ao ideal da psicologia clássica. A sua introdução significa o fim da hegemonia da introspecção, pois se refere a fatos psicológicos cujo sujeito não tem conhecimento direto, ou que não lhe são fornecidos numa intuição imediata, admitindo-se, assim, todo um conjunto de fatos psicológicos que não são dados “para si”, sendo preciso recorrer a outros métodos para se ter conhecimento deles (POLITZER,1998:169).

\section{V - A PROPÓSITO DA CONSTRUÇÃO NOCIONAL}

A preocupação de Politzer não é apenas apontar os erros da psicanálise e mostrar sua impotência quando esta volta à abstração. A sua preocupação é reconhecer e desembaraçar, em meio à prática e à teoria psicanalítica, elementos que possam indicar, em sua pureza, a psicologia concreta (POLITZER,1998:163). Assim, “diante do espetáculo da riqueza das descobertas psicanalíticas e da pobreza da psicologia clássica, as especulações

\footnotetext{
${ }^{7}$ Esquema intelectualista: primazia da representação sobre o ser, da atitude reflexiva/descritiva sobre a vida.
}

(C) ETD - Educação Temática Digital, Campinas, v.8, n.esp., p.103-120, dez. 2006 - ISSN: 1676-2592. 
abstratas da psicanálise oferecem um paradoxo que chama imperiosamente a crítica" (POLITZER,1998:163). Trata-se de uma tarefa positiva que diz respeito não apenas à maneira de definir o fato psicológico como segmento do "drama" constituído pela vida do indivíduo particular e pelo método que pretende usar para estudá-lo, mas também considerar a psicologia concreta atuando na análise do "drama”, com noções apropriadas a seu plano e a sua inspiração (POLITZER,1998:174). Assim, é preciso mostrar que, em meio a todas as noções e hipóteses que Freud foi levado a construir, há algumas que, mesmo estando no mesmo plano das outras, já pertencem à psicologia concreta (POLITZER,1998:175), que, apesar de seu semblante abstrato, os trabalhos nocionais guardam algo da inspiração concreta nas novas descobertas (POLITZER,1998:175).

Ora, duas noções que, segundo Politzer, foram criações da psicanálise e mostram a psicologia concreta em ação são as noções de identificação e o complexo de Édipo(POLITZER,1998:175). Politzer procura mostrar que estas noções são elementares e devem servir à análise e à reconstituição do drama humano, que estas noções não são apenas segmentos da vida de um indivíduo particular, mas também grandes esquemas dramáticos que têm sua dialética própria e atravessam toda a vida do homem. As noções elementares são atos do "eu” e segmentos da vida dramática, são esquemas em primeira pessoa (POLITZER,1998:175).

Nesse sentido, a tarefa empreendida por Politzer de encontrar na psicologia do início do séc. XX, elementos que indiquem o nascimento de uma psicologia concreta foi bem sucedida, na medida em que encontra na psicanálise: a definição do fato psicológico, a definição de um método e a criação de noções próprias capazes de dizer o "drama” humano. Portanto, a psicologia concreta é apta a analisar, conforme suas próprias exigências, o drama humano do qual faz o domínio por excelência da psicologia (POLITZER,1998:175).

\section{CONSIDERAÇÕES FINAIS}

Para finalizar o texto, gostaríamos de fazer uma observação a propósito da distinção moi/je, que aparece em meio ao texto de Politzer, e sua relação com a noção de 
inconsciente. Trata-se apenas de uma observação a título de indicação, pois não foi nosso objetivo tematizar esta distinção, nem fazer uma genealogia do emprego destes termos.

Como já dissemos, Politzer emprega o pronome que indica a primeira pessoa ora utilizando o termo je, ora utilizando o termo moi. Dissemos que estes diferentes termos, existentes na língua francesa para designar a primeira pessoa, não são usados indistintamente por ele. Por exemplo, ao tratar da noção de identificação, Politzer afirma que "trata-se, para o sujeito, de ser outro ou algo outro que ele mesmo". (POLITZER,1998:175) Assim, “em vez de renunciar à mãe, identifica-se com ela, transforma-se nela e procura objetos suscetíveis de substituir seu próprio eu (moi) e que possa amar e cuidar como foi amado e cuidado pela mãe”. (POLITZER,1998:175) Mais adiante ele conclui que, “a identificação e o complexo de Édipo são precisamente atos do ‘eu’ (je) e segmentos da vida do indivíduo particular”.(POLITZER,1998:175)

É interessante observar que ao empregar o termo moi Politzer se refere aos atos do indivíduo concreto na sua atualidade, ou seja, em sua determinação singular. (POLITZER,1998:68) Mas ao mesmo tempo o indivíduo não se reduz a esta atualidade, sua vida é aberta a outras determinações. É neste sentido que o eu (je) está sempre presente nas suas determinações, seja na percepção exterior ou interior, ou no sonho, por exemplo, mas não se reduz a elas, ele as transcende. Mas transcender não significa estar além, significa que há algo mais. Seria este algo mais “o” inconsciente?

Não, assim estamos voltando à abstração. Não existe “o” inconsciente. Assim, estamos remetendo o indivíduo concreto a uma substância, enquanto, para Politzer, trata-se de pensá-lo na sua dimensão dramática. Por isso nos parece importante considerar alguns apontamentos que ele faz a propósito da noção de inconsciente. Se, por um lado, ele afirma que a introdução da hipótese do inconsciente implica um retorno à abstração, por outro, ele afirma que ela nos abre à ruptura com a psicologia clássica, pois a sua introdução, entre outras coisas, significa o fim da hegemonia da introspecção (POLITZER,1998:169), o anúncio da psicologia concreta. (POLITZER,1998:170) Nesse sentido, ele faz três afirmações que, de certo modo, expressam a sua compreensão da noção de inconsciente: o inconsciente é transcendente relativamente à consciência (POLITZER,1998:172); o inconsciente é em si mesmo incognoscível (POLITZER,1998:172), ou seja, ele não é dado 


\section{ARTIGO \\ Grupo de Estudos e Pesquisa Diferenças e Subjetividades em Educação Grupo de Leitura de Freud}

numa percepção imediata através da introspecção, e, portanto; os fatos inconscientes devem ser construídos ou, pelo menos, reconstruídos (POLITZER,1998:171), para que sejam conhecidos. Assim, afirmar a existência do inconsciente implica uma nova compreensão do sujeito, não mais como substância, não mais como consciência de si, mas como um ser fendido em múltiplas dimensões, como um ser em devir.

Empreendemos a leitura do texto de Politzer procurando acompanhar sua tarefa positiva no sentido de buscar os elementos que indiquem o nascimento de uma psicologia concreta no início do séc. XX. Ele procura realizar esta tarefa partindo do interior da psicanálise, para encontrar aí os elementos que, segundo ele, indicariam o nascimento desta psicologia. Esta tarefa teve não só um aspecto negativo, que consistiu em mostrar a sobrevivência da abstração na psicologia nascente, mas, também, um aspecto positivo, que consistiu em mostrar as potências desta nova psicologia. Esta tarefa de mostrar a potência da psicologia concreta tomou três conjuntos de questões importantes para a sua constituição enquanto ciência: definição do fato psicológico enquanto drama da vida do indivíduo particular; definição de um método de interpretação do drama, e; criação de noções próprias capazes de dizer o drama.

No entanto, se em sua tarefa positiva tratou de mostrar as potências da nova psicologia, Politzer nos alerta que a pesquisa precisa continuar (POLITZER,1998:194), pois há sempre o risco de se retornar ao realismo e à abstração. Poderíamos acrescentar, há o risco de transformar uma construção nocional em doutrina e, com isto, voltar à abstração, pois as noções devem servir à análise e à reconstituição do drama humano (POLITZER,1998:177) e, portanto, podem perder a sua utilidade. Assim, nos parece, a abstração pode voltar quando se tenta inserir o sujeito numa cena da qual ele já não faz parte, num teatro no qual ele não atua mais.

(C) ETD - Educação Temática Digital, Campinas, v.8, n.esp., p.103-120, dez. 2006 - ISSN: 1676-2592. 119 


\section{REFERÊNCIAS}

FREUD, S. Freud “A Interpretação dos Sonhos” In: Edição Standard Brasileira das Obras Psicológicas Completas de Sigmund Freud. Volumes IV e V. $2^{\circ}$ ed. Rio de Janeiro: Imago, 1987.

Guillaume, P. Manual de Psicologia. Trad. Lólio Lourenço de Oliveira e J.B. Damasco Penna. São Paulo: Companhia Editora Nacional, 1967.

MARIGUELA, Marcio Aparecido. "Do Inconsciente como Causa de Divisão do Sujeito". In: Revista Literal n 4, Escola de Psicanálise de Campinas, SP, 2001, pp. 91-100.

POLITZER, Georges. Crítica aos Fundamentos da Psicologia - a psicologia e a psicanálise. Trad. Marcos Marcionilo e Yvone M. T. da Silva. Piracicaba, SP: UNIMEP, 1998.

ROUDINESCO, Elizabeth. Dicionário de psicanálise. Trad. Vera Ribeiro e Lucy Guimarães. Rio de Janeiro: Jorge Zahar, 1998. educação pela Faculdade de Educação da Unicamp. E-mail: pastrej|@hotmail.com. 